\title{
Factors Affecting the Dimensional Property of Cotton Plain-Weft Knitted Fabrics.
}

\author{
By Ryuzo Oinuma, \\ Miyagi University of Education, Sendai.
}

\section{綿平編地の寸法特性に 影響を及ぼすいくつか の要因}

\section{1. 緒言}

よこ編地の寸法変化は生産管理や品質管理の面か ら非常に重要な問題であり，古くから多くの研究者 達によって, 編地の寸法特性や幾何学的構造に関す る研究が行われてきた.

Doyle $^{1)}$ は充分に乾燥緩和された平編地の編目密 度がループ長にのみ依存することを見出した。その 後, Munden ${ }^{2)}$ は充分に緩和された平編地では,ルー プが一定の形状に近付く，すなわち，ループ長が異 なってもループ形状は相似形に近似し得るとして, この関係 (以下, Doyle ・ Munden の法則と記す) を理論的に導くとともに，綿平編地では充分に緩和 された状態が湿潤緩和処理によって得られることを 示している.ささらに Nutting らは編地タイトネス の影響について検討し，湿潤緩和処理した平編地の 編地寸法に及ぼす影響が非常に小さいことを示して おり，Knapton ら ${ }^{4)}$ は綿平編地の寸法的安定が機械 的緩和処理（洗濯とタンブル乾燥の繰返し）あるい は化学的処理（無緊張状態でのマーセル化）によっ て得られることを示すとともに，編地タイトネスや いくつかの系要因の影響についても検討し, 綿及び

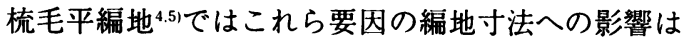
小さく，近似的には Doyle・Munden の法則が成立 つことを示している.

しかしながら, これらの研究は市販品の編地タイ トネス $\left(K=11\right.$ 15) ${ }^{6}$ の範囲内か, あるいは密な 編地を含んだ編地タイトネス $\left(K=10\right.$ 19) ${ }^{3.4}$ で行 われており, 寸法変化の大きい粗な編地については

*R. Oinuma. Member. 宮城教育大学

The effects of some factors on the dimensional parameters of plain-weft knitted fabrics $(k c=c l, k w=$ $w l, k n=k c \times k w, k s=k c / k w$ and $t / l$, where $\mathrm{c}$ and $\mathrm{w}$ are the courses/cm and wales/cm, $l$ is the loop length in $\mathrm{cm}$ and $\mathrm{t}$ is the fabric thickness in $\mathrm{cm}$ ) are investigated experimentally, using cotton paralleled yarns and plied yarns, and a nylon plied yarn.

For the coarse nylon plain-weft knitted fabrics $(K$ $=7.6-11.7), \mathrm{k}$-values are approximately constant, but $t / l$ increases with the increase of the fabric tightness $(K=\sqrt{T} / l$, where $T$ is the linear density in tex).

The results obtained for the cotton plain-weft knitted fabrics $(K=7.3-16.0)$ are as follows :

(1) $k s, k c$ and $t / l$ increase with the increase of the fabric tightness $(K)$. ks of plied yarns is dependent on the relaxation treatments (dry, wet, boil and wash), but $k s$ of paralleled yarns is not. At any fabric tightness $(K), k c$ and $t / l$ after a wash-relaxation are always more than $k c$ and $t / l$ after a dry-relaxation, and $t / l$ of paralleled yarns is always more than $t / l$ of plied yarns for all relaxations.

(2) For all yarns and relaxations, $K W$ changes little over a range of $K>11$, but changes very large over a range of $K \leqq 11$.

(3) For all yarns after a dry-relaxation, $K n$ changes little over a range of $K>10$, but changes large over a range of $K \leqq 10$. For paralleled yarns after a was$\mathrm{h}$-relaxation, kn increases with the decrease of the fabric tightness $(K)$.

ほとんど検討されていない.

そこで，本報では，まず粗なナイロン平編地（K $=7.6 \sim 11.7)$ の寸法特性について検討し，さらに, 粗な編地を含んだ綿平編地 $(K=7.3 \sim 16.0)$ の寸 法特性に影響を及ほすといくつかの要因について検 討した。

\section{2. 実験方法}

\section{1 試料布の編成と緩和処理}

綿平編地の寸法特性に影響を及ぼすと考えられる 要因として, 編地夕イトネス, 合系形態 (引揃え系, 双系, 3 子撚系), 引揃え本数及び緩和処理を取上 
げた.

使用糸として, 綿系 $20 \mathrm{~s} / 2$ (59.1 tex), $30 \mathrm{~s} / 3$ (56.2 tex), $30 \mathrm{~s} / / 2$ (39.4 tex), $30 \mathrm{~s} / / 3$ (59.1 tex), 30 s//4 (78.4 tex) 及びナイロン糸 ( 3 子撚糸 : 53.4 tex) を用いた.ナイロン糸と綿系 $30 \mathrm{~s} / 3$ は市販のミシ ン糸で, 他は全て生成糸である.

使用編機は 1 給糸口, 釜径 $4 \mathrm{in}$., 針本数 92 本の ロゴム編機の下釜のみを用いた.

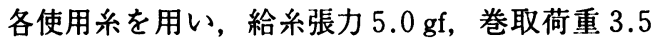
$\mathrm{kg}$ で，カムセットによってループ長を変えて平編 地を編成し，次に示す緩和処理を順に行った。通常 あまり用いられない沸水緩和処理を行ったのは, ミ シン糸の染色やセット等の糸処理の影響を除去する とともに, Suhn が指摘しているように，系の膨潤 による綿平編地の収縮をより一層促進させ得ると考 えたためである。

(1)乾燥緩和処理； $20^{\circ} \mathrm{C}, 65 \% \mathrm{RH}$ の室内に $24 \mathrm{hr}$ 以上静置し, 調湿した.

(2)湿潤緩和処理； $40^{\circ} \mathrm{C}$ の温水に $2 \mathrm{hr}$ 浸漬後, 軽 く押えて水を切り, $70^{\circ} \mathrm{C} て ゙ 2 \mathrm{hr}$ スクリーン乾 燥した後, 乾燥緩和処理と同様の方法で調湿を 行った。

(3)沸水緩和処理：沸水に $1 \mathrm{hr}$ 浸漬後, 軽く押え て水を切り, 湿潤緩和処理と同様の方法で乾燥 及び調湿を行った。

(4)洗濯緩和処理；洗濯試験機（ウオッシュシリン ダ型）を用い, $60^{\circ} \mathrm{C}$ の温水に家庭用洗剂 $5 \mathrm{~g} / \mathrm{l}$ 入れて $1 \mathrm{hr}$ 洗濯し, $60^{\circ} \mathrm{C}$ の温水で $20 \mathrm{~min}$ 間す すいだ後, 軽く押えて水を切り, 湿潤緩和処理 と同様の方法で乾燥及び調湿を行った。

\section{2 測定方法}

各緩和処理後に, ループ長, コース密度, ウェー ル密度及び編地厚さを測定し, 編地夕イトネス及び 編地寸法パラメータを算出した.

\section{(ঐ)ループ長の測定}

コースレングステスタを用い, 初荷重 10.0 gで 各試料布のコース長を 5 回ずつ測定し, その平均值 を針本数で割った值をループ長 $(l)$ とした。なお, lは cm 表示のループ哀とする.

\section{(2)編地タイトネス}

編地タイトネス $(K)$ は次式を用いて算出した(た だし，Tは tex 番手とする).

$$
K=\sqrt{T} / l
$$

\section{(3)コース及びウェール密度の測定}

40コース及び40ウェールの長さをノギス（精度：
$0.01 \mathrm{~mm}$ ) で 5 回ずつ測定した值の平均値から, $\mathrm{cm}$ 当りのコース数 $(\mathrm{c})$ 及びウェール数 $(\mathrm{w})$ を算出し た。

\section{(4)蝙地寸法パラメータ}

編地寸法パラメー夕 $(k c, k w, k n$ 及び $k s)$ は次 に示す Doyle・Munden の法則8.99を用いて算出した.

$$
\begin{aligned}
& k c=c l \\
& k w=w l \\
& k n=k c \times k w \\
& k s=k c / k w
\end{aligned}
$$

\section{(5)满地厚さの测定}

加圧式厚さ測定器を用い, $7 \mathrm{~g} / \mathrm{cm}^{2}$ の加圧下で各 試料布の厚さ $(t)$ を測定し, その平均値で示した. なお, $t / l$ は $\mathrm{cm}$ 表示の厚さとループ長の比で示し た.

\section{3. 実験結果と考察}

\section{1 ナイロン平編地}

表 1 に粗なナイロン平編地の緩和処理に伴う編地 タイトネス $(K)$ と編地寸法パラメータ $(k c, k w$, $k n$ 及び $k s)$ 及び $t / l$ との関係を示す. なお, 平均値 と変動係数 C.V. \%は緩和処理及び編地夕イトネス におけるデータ（データ数：15）をプールして求め た值である。

表 1 からわかるように, $k c$ は編地夕イトネスや 紘和処理とはほとんど無関係にほぼ一定の值を示し ている。，一方，kw, $k n$ 及び $k s$ は編地夕イトネス及 び緩和処理と無関係でなく，いずれの緩和処理にお いても, 編地夕イトネスの增加に伴い $k w$ 及び $k n$ は増加し, $k s$ は減少し, さらに, 乾燥, 湿潤及び 沸水緩和処理の順に, いずれの編地タイトネスにお いても, $k w$ 及び $k n$ は増加し, $k s$ は減少する. しか し, 編地タイトネス及び緩和処理に伴う変化はわず かであり,ナイロン平編地では粗な編地でも, 編地 タイトネスや緩和処理に関係なく，近似的には Doyle・Munden の法則が成立つことを示している.

編地の厚さについては, Postle ${ }^{6 /}$ が理論的解析を もとに羊毛平編地では $t / l=0.147$ になることを示 しており，Knaptonらは綿平編地では編地タイト ネスと $t / l$ との間には直線関係 $(t / l=0.007 K+$ 0.096）があることを示し，かつ切片が 0 にならな いのは, ループ側面の弯曲の程度が影響するためで あろうということを示している.

表 1 からわかるように，緩和処理に関係なく， $t / l$ は編地夕イトネスの増加とともに直線的に増加 
表 1 ナイロン平編地の編地タイトネスと 䌃地寸法パラメータ及び $t / l$

\begin{tabular}{|c|c|c|c|c|c|c|}
\hline & $K$ & $k c$ & $k w$ & $k n$ & $k s$ & $t / \ell$ \\
\hline \multirow{5}{*}{ 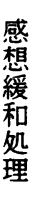 } & 7.60 & 4.90 & 3.40 & 16.7 & 1.44 & 0.067 \\
\hline & 8.39 & 4.94 & 3.46 & 17.1 & 1.43 & 0.076 \\
\hline & 9.32 & 4.93 & 3.49 & 17.2 & 1.41 & 0.085 \\
\hline & 10.23 & 4.98 & 3.59 & 17.9 & 1.39 & 0.095 \\
\hline & 11.64 & 4.94 & 3.64 & 18.0 & 1.36 & 0.110 \\
\hline \multirow{5}{*}{ 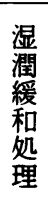 } & 7.65 & 4.93 & 3.49 & 17.2 & 1.41 & 0.067 \\
\hline & 8.45 & 4.88 & 3.56 & 17.4 & 1.37 & 0.077 \\
\hline & 9.37 & 4.91 & 3.56 & 17.5 & 1.38 & 0.087 \\
\hline & 10.29 & 4.95 & 3.68 & 18.2 & 1.35 & 0.096 \\
\hline & 11.67 & 4.92 & 3.72 & 18.3 & 1.32 & 0.112 \\
\hline \multirow{5}{*}{$\begin{array}{l}\text { 沸 } \\
\text { 水 } \\
\text { 緩 } \\
\text { 処 } \\
\text { 理 }\end{array}$} & 7.70 & 4.94 & 3.55 & 17.5 & 1.39 & 0.068 \\
\hline & 8.50 & 4.85 & 3.66 & 17.8 & 1.33 & 0.077 \\
\hline & 9.42 & 4.89 & 3.69 & 18.0 & 1.33 & 0.088 \\
\hline & 10.35 & 4.89 & 3.77 & 18.4 & 1.30 & 0.097 \\
\hline & 11.71 & 4.90 & 3.82 & 18.7 & 1.28 & 0.114 \\
\hline \multirow{2}{*}{\multicolumn{2}{|c|}{$\begin{array}{c}\text { 平均 値 } \\
\text { C.V.\% }\end{array}$}} & 4.92 & 3.61 & 17.7 & 1.37 & - \\
\hline & & 0.6 & 3.2 & 3.0 & 3.4 & - \\
\hline
\end{tabular}

しており, 回帰式 (デー夕数：15）を求めると次の ようになる $(r=0.999)$.

$$
t / l=0.011 K-0.017
$$

この式は Knapton らの結果とほほ同じような傾 向を示しているが，傾きが大きくなり，切片が $0 に$ 近付く．これは紡績系である綿糸とフィラメント糸 であるナイロン系との違いに起因するものと考えら れる.

\section{2 綿平編地}

編地寸法に影響を及ぼす要因として，取上げた要 因以外にも給系張力 $(5.0,15.0,25.0 \mathrm{gf})$ や巻取 荷重 $(3.5,5.4,7.0 \mathrm{~kg})$ についても検討したが, これらの要因はループ長を変えることによってのみ 編地寸法パラメー夕に影響することがわかった。す なわち, 給系張力や巻取荷重によってループ長を変 えても，カムセットによってループ長を変えても， ループ長と編地寸法パラメータとの関係にはほとん ど差異が認められなかった，そのため，本報では， カムセットによってループ長を変えて試料布を編成 した。

引揃え本数によって系番手を変えた場合の編地夕 イトネス $(K)$ とループ形状パラメータ $(k s)$ との 関係を図 1 に示す.

図1からわかるように, ks は編地夕イトネスの 増加とともにほぼ直線的に増加している。

図 1 には示していないが, 湿潤及び沸水緩和処理

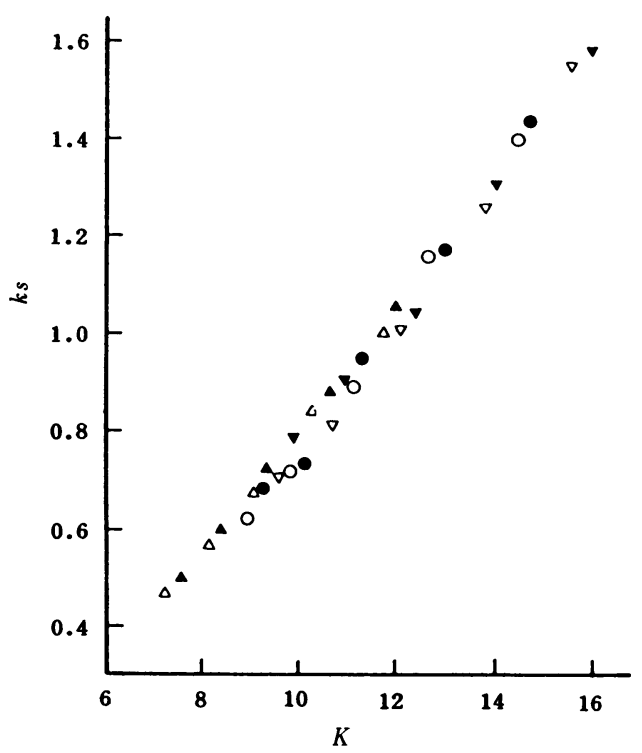

図 1 編地タイトネス $(K)$ に伴う $k s$ の変化 $\triangle: 30 \mathrm{~s} / / 2, \bigcirc: 30 \mathrm{~s} / 3, \nabla: 30 \mathrm{~s} / 4, \Delta, \bigcirc, \nabla$ : 乾燥緩和, $\Delta, \boldsymbol{O}, \boldsymbol{\nabla}:$ 洗濯緩和

の場合にもほとんど同じ傾向を示すので, 各緩和処 理におけるデータをプールして回帰式を求めると (デー夕数：60), 次のようになる $(r=0.995)$.

$$
k s=0.135 K-0.58
$$

(7)式から,引揃え糸では, ループ形状パラメータ (ks) は引揃え本数や緩和処理には関係なく, 編地 タイトネス $(K)$ にのみ依存することがわかる.

同一番手で合系形態 $(20 \mathrm{~s} / 2,30 \mathrm{~s} / 3,30 \mathrm{~s} / / 3)$ を変えた場合の編地タイトネス $(K)$ とループ形状 パラメータ $(k s)$ との関係を図 2 に示す。

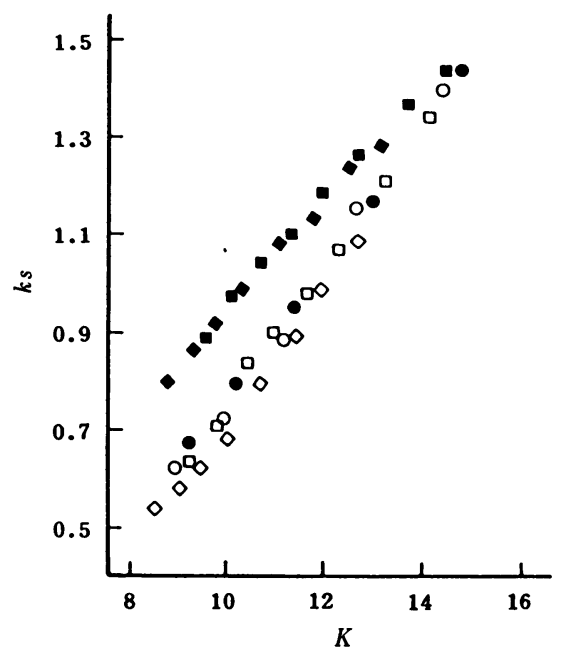

図 2 編地タイトネス $(K)$ に伴う $k s$ の変化 $\square: 20 \mathrm{~s} / 2, \bigcirc: 30 \mathrm{~s} / 3, \diamond: 30 \mathrm{~s} / 3, \square, \bigcirc, \diamond$ : 乾燥緩和, 
図 2 からわかるように, いずれの緩和処理の場合 も $k s$ は編地夕イトネスの增加とともにほほ值線的 に増加している．乾燥緩和処理では合系形態による 差異はほとんど認められないが，洗濯緩和処理では 引揃え糸が前述したように乾燥緩和処理とほほ同じ 変化を示し，諸撚系（20 s/2,30 s/3）は乾燥緩和 処理とは異なる値を示している．図 2 には示してい ないが, 湿閏及び沸水緩和処理の場合もほぼ同じよ うな傾向を示している，換言すれば，諸撚系では， 乾燥, 湿潤, 沸水及び洗濯緩和処理の順に, 同一の $K$ における $k s$ の值が大きくなり，かつ $K$ に伴う $k s$ の変化が減少する. すなわち, 同一番手の諸撚系で は, ループ形状パラメータ $(k s)$ は諸撚系の合系数 には関係なく，編地タイトネス及び緩和処理に依存 することがわかる.

編地夕イトネス $(K)$ に伴う $k c$ 及び $k w$ の変化を 図 3 に示す.

図 3 からわかるように, $k c$ はいずれの緩和処理 の場合も合糸形態に関係なく, 編地夕イトネスの増 加とともにほぼ直線的に増加する.

図 3 には湿潤及び沸水緩和処理における $k c$ の変

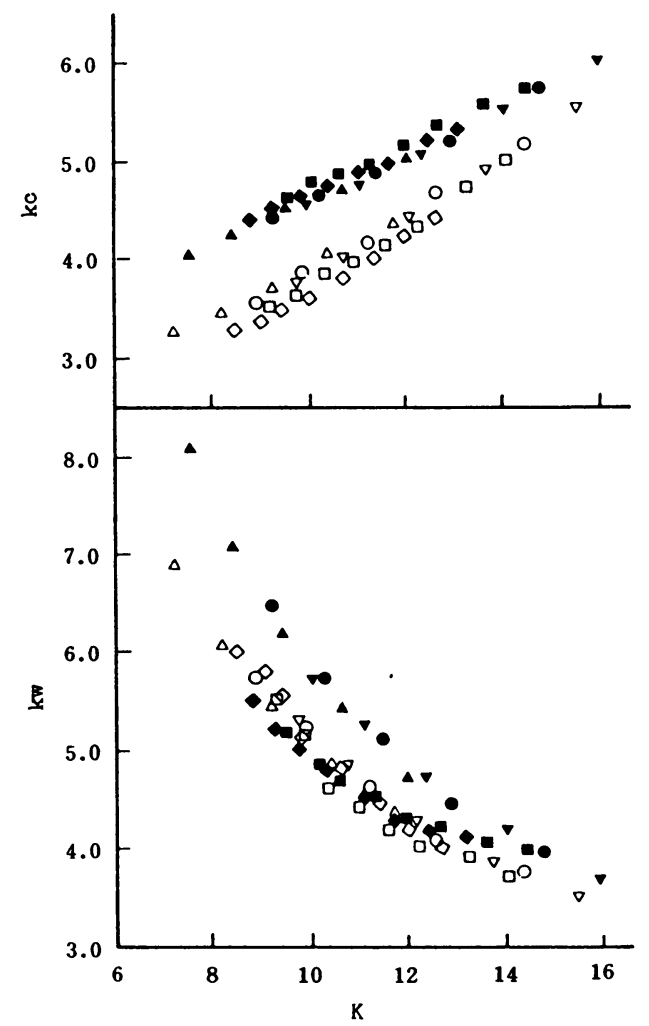

四 3 編地夕イトネス $(K)$ に伴う $k c$ 及び $k w$ の変 化

$\Delta: 30 \mathrm{~s} / 2, \quad \bigcirc: 30 \mathrm{~s} / / 3, \nabla: 30 \mathrm{~s} / 4, \quad \square: 20 \mathrm{~s} / 2$, $\diamond: 30 \mathrm{~s} / 3, \Delta, \bigcirc, \nabla, \square, \diamond:$ 乾燥緩和, $\Delta$,

๑, $\nabla, \mathbf{\square}, \bullet:$ 洗濯䌅和
織 維 機 械 学会誌

化は示していないが, 乾燥, 湿潤, 沸水及び洗濯緩 和処理の順に, 同一の $K$ における $k c$ の值が大きく なり，かつ $K$ に伴う $k c$ の変化が減少する. すなわ ち, $k c$ は合系形態には関係なく, 編地タイトネス 及び緩和処理に依存することがわかる.

一方, $k w$ はいずれの緩和処理及び合糸形態の場 合も, 編地タイトネスの減少とともに非線形に増加 する. $K=11$ 以上における $k w$ の変化は小さいが, $K=11$ 以下では $K$ の減少とともに $k w$ が急激に増 加する。乾燥緩和処理では合系形態による差異はほ とんど認められないが, 洗濯緩和処理では乾燥緩和 処理に比べ， $K$ に伴う $k w$ の変化は引揃え系の場合 には増加し，諸撚系の場合にはわずかに減少する. すなわち, $k w$ は引揃え系では, 編地夕イトネス及 び緩和処理に依存し，諸撚糸では緩和処理の影響は ほとんどなく，編地タイトネスに依存することがわ かる.

編地タイトネス $(K)$ に伴う面積パラメータ $(k n)$ の変化を図 4 に示す.

図 4 からわかるように, $K$ に伴う $k n$ の変化は乾 燥緩和処理における引揃え系及び諸撚系と洗濯緩和 処理における諸撚系とはほほ同じ傾向を示してい る. すなわち, $K=12$ 以上では $K$ の増加とともに $k n$ もわずかに増加し， $K=10$ 12 ではあまり変化 せず, $K=10$ 以下では $K$ の減少とともに $k n$ は増 加する. 同一の $K$ における $k n$ の值は乾燥緩和処理

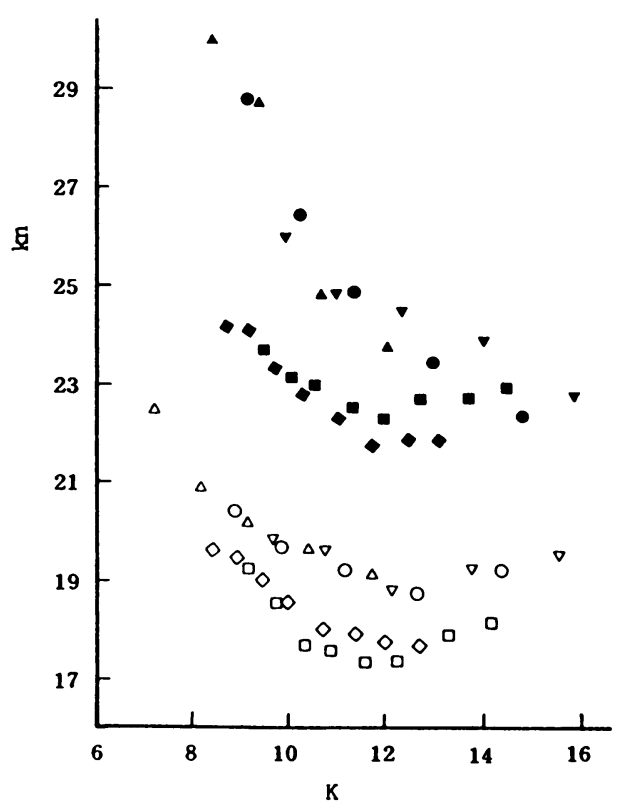

図 4 編地タイトネス $(K)$ に伴う $k n$ の変化 $\triangle: 30 \mathrm{~s} / / 2, \bigcirc: 30 \mathrm{~s} / / 3, \nabla: 30 \mathrm{~s} / 4, \square: 20 \mathrm{~s} / 2$, $\diamond: 30 \mathrm{~s} / 3, \Delta, \bigcirc, \nabla, \square, \diamond:$ 乾燥緩和, $\Delta$, $\checkmark, \nabla, \square$, : 洗濯緩和 
(綫維工学) Vol. 39, No. 11 (1986)

での諸撚系, 引揃え系, 洗濯緩和処理での諸撚系の 順に大きくなる，一方，洗濯緩和処理における引揃 え糸では, $K$ の隇少に伴い $k n$ は非線形に增加し,

特に $K=10$ 以下では $K$ の減少に伴う $k n$ の増加が 急激になる. しかし，いずれの場合も $K=10$ 以上 での変化率に比べ， $K=10$ 以下での変化率が増大 する傾向を示している.

ほほ同一の編地タイトネス $(K \doteqdot 11)$ の場合の 緩和処理に伴う面積パラメー夕 $(k n)$ の変化を図 5 に示す.

図 5 からわかるように，引揃え系では引揃え本数 に関係なく，諸撚系では合系本数に関係なく，ほほ 同じような挙動を示しているが, いずれの緩和処理

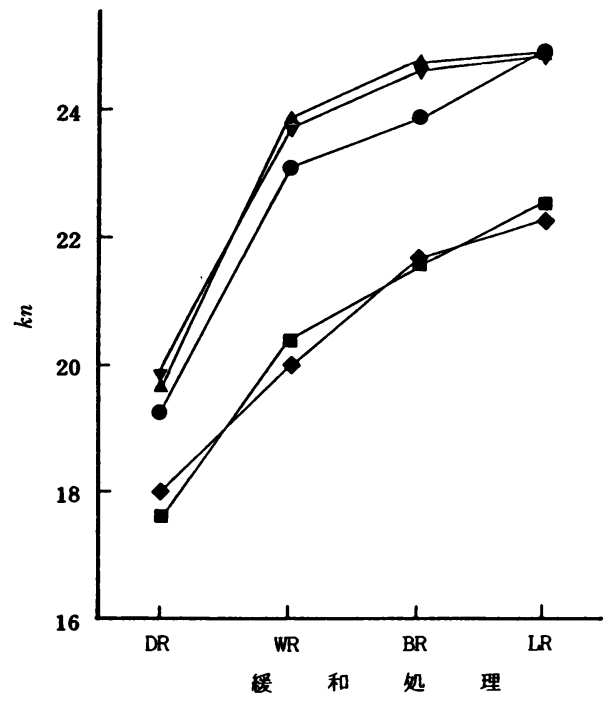

図 5 緩和処理に伴う $k n$ の変化 $(K \doteqdot 11)$

$\Delta: 30 \mathrm{~s} / / 2, \bigcirc: 30 \mathrm{~s} / / 3, \nabla: 30 \mathrm{~s} / / 4, \square: 20 \mathrm{~s} / 2$, : $30 \mathrm{~s} / 3$, DR : 乾燥緩和, WR : 湿潤緩和, BR : 沸水緩和, LR：洗灌緩和

においても，knの值は諸撚糸より引揃え糸の方が 大きい. 湿潤及び沸水緩和処理における $k n$ の増加, すなわち，面積収縮はおそらく $\mathrm{Suh}^{7}$ が指摘してい るように糸の膨潤によるものと考えられる.さらに, 洗濯緩和処理により面積収縮が生じているが, 沸水 緩和処理までの面積収縮に比べるとかなり少ない。 この収縮はループ相互の接点における糸の移動ある いは Knapton ら"が指摘している分子の再配列によ るものと考えられる.

Knapton ら"1化学的緩和処理によっても，機械 的緩和（洗濯とタンブル乾燥の繰返し）と同様な効 果が得られることを示すとともに, 編地の緩和が瀻 維内での分子の再配列によって生ずるのであろうと いうことを示している.

引揃え系 $(30 \mathrm{~s} / / 3)$ 及び諸撚系 $(20 \mathrm{~s} / 2)$ で編地
タイトネス $(K)$ を変えて編んだ綿平編地の緩和処 理に伴う面積パラメー夕 $(\mathrm{kn})$ の変化を図 6 及び図 7 に示す.

図 6 からわかるように，引揃え系 $(30 \mathrm{~s} / / 3)$ では 緩和処理に伴う $k n$ の変化が $K$ の減少とともに増大

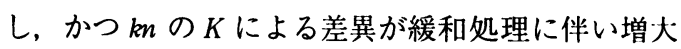
する傾向を示している. 一方, 諸然系 $(20 \mathrm{~s} / 2)$ で は $k n$ のによる差異はあまり明確でなく，かつ緩 和処理に伴う $k n$ のバラッキも幾分減少する傾向を 示す. すなわち, 緩和処理に伴う $k n$ の変化は, 引 揃え糸では編地タイトネスによって異なった挙動を 示すが, 諸撚系では編地タイトネスによる差異はあ まり明確でなく、ほぼ同じような挙動を示している.

編地タイトネス $(K)$ に伴う $t / l$ の変化を図 8 に 示す.

図 8 には示していないが, 湿潤及び沸水緩和処理 の場合もほぼ同じような傾向を示す，すなわち，い ずれの合系形態及び緩和処理の場合にも, $t / l$ は $K$ の増加とともにほぼ直線的に増加する. 又, いずれ の緩和処理においても $t / l$ は諸撚系より引揃え系の 方が大きな值を示し，かつ引揃え系及び諸撚系いず れの場合も $t / l$ の值は乾燥, 湿潤, 沸水及び洗濯緩 和処理の順に大きくなる. 洗濯緩和処理における $K$ と $t / l$ との回帰式を求めると, 引揃え系（デー夕数 $: 15, r=0.995)$ では,

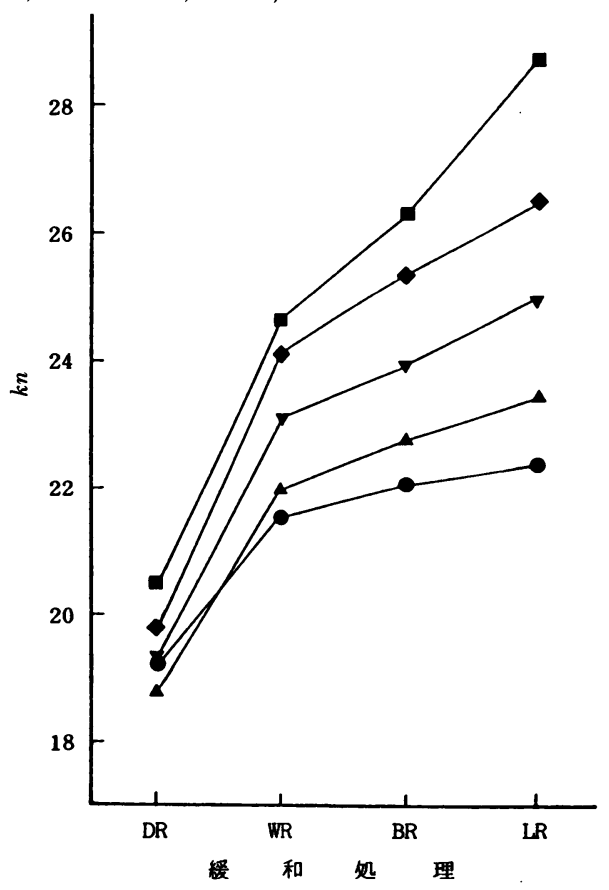

図 6 緩和处理に伴う $k n$ の変化 $(30 \mathrm{~s} / / 3)$

- $: K=14,6, \Delta: K=12.8, \nabla: K=11.3$, $: K=10.1, \square: K=9.3$, DR : 乾燥緩和, WR : 湿潤緩和, BR : 沸水緩和, LR : 洗濯緩和 


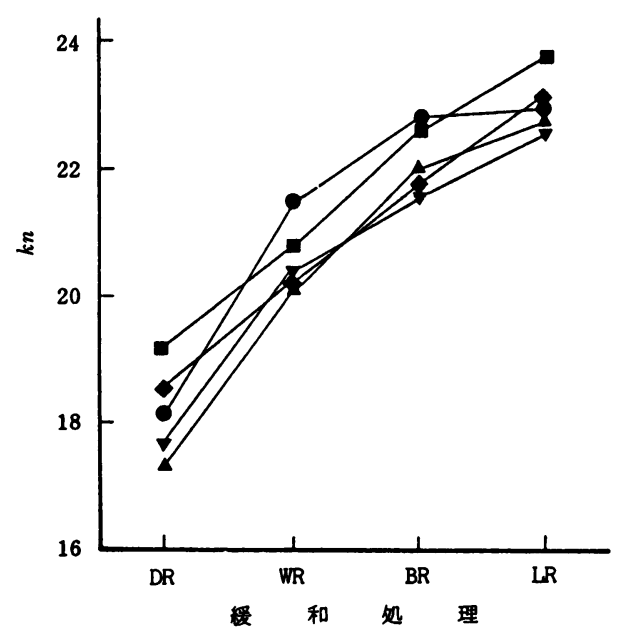

図 7 緩和処理に伴j $k n$ の変化 $(20 \mathrm{~s} / 2)$

- $K=14.3, \Delta: K=12.5, \nabla: K=11.1$, $: K=10.0, \square: K=9.4, \mathrm{DR}:$ 乾燥緩和, WR : 湿潤緩和, BR：沸水緩和, LR : 洗濯緩和

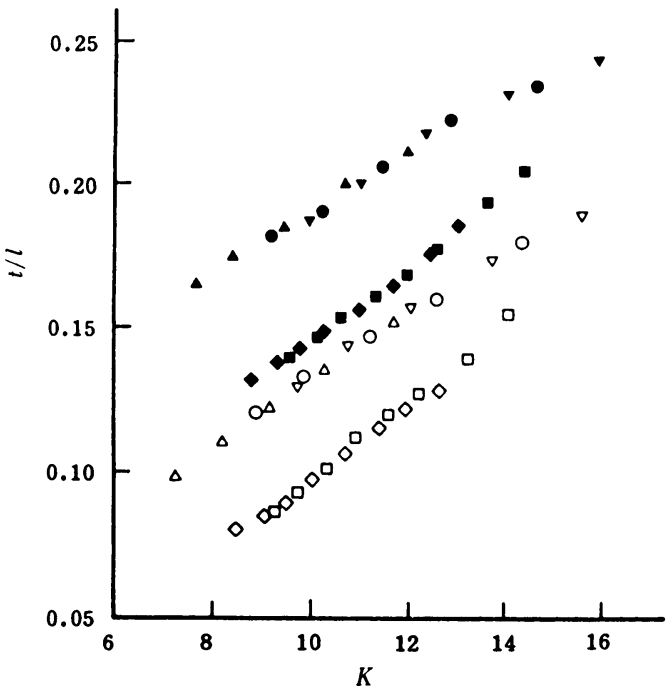

図 8 編地タイトネス $(K)$ に伴う $t / l$ の変化 $\triangle: 30 \mathrm{~s} / / 2, \bigcirc: 30 \mathrm{~s} / / 3, \nabla: 30 \mathrm{~s} / 4, \square: 20 \mathrm{~s} / 2$, $\diamond: 30 \mathrm{~s} / 3, \Delta, \bigcirc, \nabla, \square, \diamond:$ 乾燥緩和, $\Delta$, $\checkmark, \nabla, \square$, 流濯緩和

$t / l=0.010 K+0.094$

諸撚系（デー夕数：16, $r=0.996 ）$ では,

$t / l=0.013 K+0.019$

となる。これらの式を前述したナイロン平編地での (6)式と比較すると，傾きはほぼ同じであるが，切片 は諸然系では幾分大きくなり, 引揃え系ではかなり 大きくなる．Knapton らの式价と比べると，引揃え 系では傾きが増加し，切片がわずかに減少し，諸撚 系では傾きがかなり増加し, 切片がかなり減少して いる．しかし，引揃え系及び諸撚系ともに，洗濯緩 和処理における $t / l$ は編地タイトネスに依存してい
ることがわかる.

\section{4. 結 論}

本報では, 粗なナイロン平編地（ $K=7.6 \sim 11.7 ）$ の寸法特性について検討し, さらに, 粗な編地を含 んだ綿平編地（ $K=7.3 〜 16.0 ）$ の寸法特性に影響 を及ぼすいくつかの要因について検討した.

ナイロン平編地では, 粗な編地でも編地寸法パラ メータへの編地タイトネスや緩和処理の影響は少な く, 近似的には Doyle・Munden の法則が成立つ。 さらに, $t / l$ は緩和処理には関係なく, 編地夕イト ネスのみに依存する.

綿平編地の寸法特性に及ほすすいつかの要因の影 響をまとめると，次のようになる。

(1)ループ形状パラメータ (ks) は引揃え系では緩 和処理には関係なく編地夕イトネスにのみ依存 するが, 諸然系では緩和処理により編地夕イト ネスの影響が減少する。

(2) $k c$ は合系形態に関係なく，編地夕イトネスに 依存するが, 緩和処理により編地夕イトネスの 影響が減少する.

(3) $k w$ は $K=11$ 以上では編地夕イトネスの影響 が少ないが, $K=11$ 以下では $K$ が小さくなる ほど編地タイトネスの影響が大きくなり, 引揃 え系では緩和処理に伴いその傾向が増大する.

(4) $k n$ は $K=10$ 以上では編地夕イトネスの影響 は非常に少ないが， $K=10$ 以下では $K$ が小さ くなるほど編地タイトネスの影響が大きくな り, 引揃え系では緩和処理に伴いその傾向が増 大する.

(5) $t / l$ は編地タイトネスの增加とともにほぼ直線 的に増加し，緩和処理に伴い同一の $K$ での $t / l$ の值は増加する。

（付記）本研究を行うに際して,ご指導いただいた 山形大学工学部小川敬之名誉教授, 竹田啓 助教授に深く感謝する.

\section{参考文献}

1) P. J. Doyle ; J. Text. Inst., 44, P 561 (1953)

2) D. L. Munden : J. Text. Inst., 50. T 448 (1959)

3) T. S. Nutting. G. A. V. Leaf; J. Text. Inst.. 55. T 45 (1964)

4) J. J. F. Knapton, E. V. Truter, A. K. M. A. Aziz ; J. Text. Inst., 66. 413 (1975)

5) J. J. F. Knapton, W. Fong; Text. Res. J., 41, 894 (1971)

6) R. Postle ; J. Text. Inst., 65, 155 (1974)

7) M. W. Suh ; Text. Res. J., 37, 415 (1967)

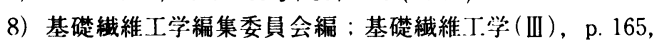
日本䄉維機械学会 (1972)

9) J. J. F. Knapton : Knitted Outerwear Times, 36. (41), 48 (1967) 